\title{
International education and economic growth
}

\author{
Jan Bergerhoff ${ }^{{ }^{*}}$, Lex Borghans², Philipp K Seegers ${ }^{2 *}$ and Tom van Veen 2,3,4
}

\author{
*Correspondence: \\ j.bergerhoff@uni-bonn.de; \\ p.seegers@maastrichtuniversity.n \\ ${ }^{1}$ Bonn University, Bonn, Germany \\ ${ }^{2}$ Maastricht University, Maastricht, \\ Netherlands \\ Full list of author information is \\ available at the end of the article
}

\begin{abstract}
In recent years international student mobility increased. While net hosting countries are in a better position to win highly educated students for their labour force, they face the additional cost of providing the education. In much of continental Europe these costs are not levied on students, but are borne by the national tax payers, making them an active topic of debate. Borrowing some fundamental equations from the Lucas growth model, this paper addresses the question whether countries benefit from educating international students. We derive conditions under which international education has a positive effect on economic growth, overall and in each specific country. Based on empirically motivated parameter values to calibrate our two-country model we find that international student mobility increases steady state growth for both countries on average by 0.013 percentage points. A small country that is favoured by the inflows of a larger country could experience an extra growth of 0.049 percentage points. The benefits from international education increase when a country tunes its education and migration policy.
\end{abstract}

JEL Classification: 125.

Keywords: International education, Economic growth, Economics of education

\section{Introduction}

Education is generally viewed as an important determinant for economic growth. In recent years, international mobility of students in higher education has increased substantially and further growth is expected. This raises the question how the international flows of students will affect economic growth in general and in particular in those countries that either receive or send many students.

The aim of this paper is to develop an endogenous growth model that incorporates the international mobility of students and to calibrate the model to investigate potential growth effects of internationalisation in higher education. We do this by building a twocountry model, in which a fraction of the students in higher education studies abroad, around the human capital accumulation equation from Lucas (1988). We assume that the host country pays the direct costs of the university. Based on the literature we look for plausible values for the parameters in the model and the uncertainty in these estimates. Based on this we simulate potential growth profiles for countries that send or receive students. Our main findings are that total growth of both countries together always increases in steady state. Countries that receive a large group of foreign students who stay after their study will have a larger than average steady state growth rate. At the same time countries that receive a net surplus of students face an immediate negative shock in income

() 2013 Bergerhoff et al.; licensee Springer. This is an Open Access article distributed under the terms of the Creative Commons Attribution License (http://creativecommons.org/licenses/by/2.0), which permits unrestricted use, distribution, and reproduction in any medium, provided the original work is properly cited. 
when internationalisation increases. Receiving a large share of international students, thus, leads to a lower income at first but will benefit the country in the long run. This payback period is shorter if the fraction of foreign students that stay is larger. An international labour market that easily adopts home-educated foreign students therefore complements access for international students to the universities.

The question how internationalisation in higher education affects economic growth has important policy implications in the debate about the European market for higher education. While in countries like Australia, the US and the UK foreign students pay a fee that covers the costs of higher education, this is not true for European students that want to study in another European country. The Bologna agreement has created a common market for higher education in Europe comparable to the common market that already exists in the Anglo-Saxon World. There is, however, one main difference between the two models. Whereas in Anglo-Saxon countries tuition fees differ between locals/nationals and foreigners (in the US they even differ between in-state and out-of-state students and in addition between US and foreign students), this difference does not exist in Europe. Freedom of settlement in Europe implies that all European students must be treated the same and hence pay the same tuition fees as domestic students. For the Netherlands, for example, this implies that all European students pay the Dutch tuition fee of about 1.800 per year. For Germany this means that all European students can study for free at a number of German universities. Governments are therefore confronted with the question whether they should promote the inflow of foreign European students or should make it less attractive for foreign European students to study in their country, and perhaps encourage their own students to study abroad.

This paper is related to literature about the returns to education and endogenous growth. Economists have been capturing the effect of education on economic growth into a series of growth models, which go back to the Solow growth model. These models manage to capture a broad range of the features associated with education, such as positive externalities and opportunity costs included in Lucas (1988) or the necessary monetary investment in Mankiw et al. (1992). Research shows that an investment in education is a profitable investment: in his overview of empirical research McMahon (2004) finds that the private rate of return on education is around 10 percent while the social rate of return is around 17 percent for OECD countries. Empirical evidence confirms the positive effect of education on economic growth. The key driver of this relation is the positive relation between education and productivity.

The paper also relates to the literature on student mobility. Existing endogenous growth models assume that graduates stay in the country after finishing their studies. But with increasing globalisation and increasing (student) mobility, graduates do not automatically stay in the country in which they have been educated. This does not only hold for European students: in particular the BRIC countries have been very active in changing the brain drain into a brain gain by attracting natives who have been educated abroad, back to their home-country. On the other hand, part of the international student population is expected to stay in the host country. This changes human capital as well as the labour force in a given country and consequently leads to interesting growth effects. What happens when the net flow of students for a country is negative? Do all countries benefit from educational globalisation? These questions can be answered from the analysis of this paper. Similarly, countries subsidising many foreign students query whether the expected 
benefits exceed the cost of providing the education. With many students able to move to their desired place of study, educational protectionism could soon be a matter of debate. We focus on the relation between educating foreign students and economic growth and take two specifics of international education into account: first the costs that are involved if graduates leave the country after graduation and second the mobility of graduates.

The analysis in this paper are based on the assumption that studying abroad may benefit some students. This could be either because the quality of universities in another country is better in general, or because the match between student and university may improve. Internationalization could also enhance economic productivity because of the cultural experience that students obtain in foreign education as argued by Menchtenberg and Strausz (2008): "The development of multi-cultural skills are seen as indispensable in a European Union that strives for full economic integration while preserving the diversity of its cultures" (Mechtenberg and Strausz, p. 110). Alternatively, international education might also increase cultural intelligence. We contribute to this literature by showing the relevance of the added value of international education for economic growth. In addition we take both the sending and the receiving country into account and discuss the relation between internationalisation of education and internationalisation of the labour market via migration.

This paper is organised as follows. Section 2 presents the model. In section 3 we discuss the parameter values that we use to simulate the model. The results of the simulation are presented in section 3.2. Section 4 concludes.

\section{The model}

\subsection{Basic equations}

Our model represents a "Solow style" simplification of the Lucas model Lucas ${ }^{1}$ (1988). To model international flows of students we extent the model by introducing a second country called Foreign, whose variables are marked by asterisks. Our domestic county is called Home. Production in the model takes place in a similar fashion as in the original Lucas Model where output depends on capital and effective workers. The latter consist of the total labour force $L$ times the share of workers $v$ and the stock of human capital $h$

$$
Y=K^{\alpha}(v h L)^{(1-\alpha)}
$$

Investment into physical capital is derived from a constant savings rate $s$ and depreciates at a constant rate $\delta$

$$
\dot{K}=s Y-\delta K \text {. }
$$

As in the Lucas model, education is necessary for the creation of human capital. Imagine a world where there exist three different types of individuals: Workers $(v L)$, students $(u L)$ and teachers $((1-u-v) L)$. Students can either receive their education domestically with productivity $\rho$, or they can go abroad and receive foreign education. The productivity of such international education $\phi$ is the sum of the domestic productivity in the foreign country $\rho^{*}$ and an international premium $\epsilon$. Similarly, $\phi^{*}$ is the sum of the domestic productivity $\rho$ and the international premium for foreign students $\epsilon^{*}$. The term productivity in this context refers to the rate at which students accumulate new human capital. This 
parameter could be heterogeneous among students. If the productivity of foreign education together with the international premium is below the productivity of domestic education it makes no sense for a student to study abroad.

We assume that the productivities of education are exogenous. This is a limitation to the model as the rate of internationalisation could have an effect on the productivities. The direction of this effect, however, is so far not determined and could be positive as well as negative. For this reason and to keep the model simple we assume the productivities to be fixed. The growth of human capital can be described as:

$$
\begin{aligned}
& \dot{h}=h u\left((1-i) \rho+i(1-\lambda) \phi+R i^{*} \lambda^{*} \phi^{*}\right), \\
& \quad \text { where } R=\frac{u^{*} L^{*}}{u L} ; \phi=\rho^{*}+\epsilon \text { and } \phi^{*}=\rho+\epsilon^{*} .
\end{aligned}
$$

The structure of this equation is same as in Lucas. In fact, when setting the percentage of students that study abroad $i$ equal to zero, the equation gives back Lucas' equation where $\dot{h}=h u \rho$. The difference to Lucas here is the term in the parentheses, which is a weighted average of the different educational productivities. The first element $(1-i) \rho$ weights the domestic productivity of education by the percentage of Home students enrolling in domestic education. The second term $i(1-\lambda) \phi$ looks at the percentage of Home students that decide to obtain education in the foreign country at productivity $\phi$ and return to the Home. Since it can be expected that students will only study abroad when they benefit from this we assume that $\phi=\rho^{*}+\epsilon>\rho$ and $\phi^{*}=\rho+\epsilon^{*}>\rho^{*}$. It is a feature of our model that students who obtain education in the other country might not return to their country of origin. The parameter $\lambda$ captures this probability to stay. The second term, therefore, only includes those international students in Home's human capital growth that also return to the country. The last element considers the international students from the foreign country that decide to study and stay in Home. It is additionally weighted by the relative size of the two countries student populations $R=\frac{u^{*} L^{*}}{u L}$. This is important because if, for example, Foreign was four times the size of Home and had the same values for $i$ and $u$, Home would see four times more students coming into the country than leaving it for education. Overall, this equation introduces productivity differences and the concept of brain drain and brain gain to human capital formation.

The original Lucas model does not explicitly distinguish between teachers and students. A fraction $u$ of the workforce is not working in the productive sector but puts effort in learning. This fraction $u$ includes both students and teachers, while $\rho$ is the productivity of teachers and students together. In our extension we need to distinguish students from teachers, since we assume that teachers always come from the Home country, while students might also come from the Foreign country. Our fraction $u$ therefore only refers to the fraction of students in the population and is thus lower than $u$ in the Lucas model. Moreover, our $\rho$ refers to the productivity of students in learning and will therefore be larger than $\rho$ in the Lucas model which refers to students and teachers.

A necessary condition for students to accumulate any human capital is the availability of teachers. While students and teachers produce human capital together, we assume that only students can store human capital. Moreover, we take as given that at any point in time there exists the same ratio between teachers and students $\theta$ in both countries. This assumption enables us to effectively account for the costs of education and to leave 
out teachers from the human capital accumulation equation. Note that the introduction of teachers was not necessary to account for the cost of producing human capital in the original model as there were no international students. Moreover, the teacher student ratio should also have an impact on educational quality. This relation is skipped for simplicity as both the student teacher ratio and the productivity of education are exogenous. Assuming that both countries have the same teacher student ratio, $\theta$, we define the share of workers as anybody who is neither a student nor a teacher. As a result, the costs of education per student will be very similar in the two countries. The share of workers in the population is then given by

$$
v=1-u-u \theta\left(1-i+R i^{*}\right) .
$$

Student migration has a direct effect on the population size in both countries. We look at two different scenarios with respect to the balancing of migration flows. In the first scenario we assume that the population size of both countries is constant. Consequently, the growth in the population through channels other than student migration (the birth rate or migration of unskilled workers) has to counterbalance the student migration flows. In the second scenario we will assume that student mobility will cause changes in the population size of the two countries. Here we assume all other causes of population growth to be absent. Consequently the country that net receives most students will face a population growth while the other country will face a reduction in its population.

\subsection{Solution}

To be in steady state, capital per effective capita needs to be constant.

$$
\begin{aligned}
\frac{\dot{K}}{h L} & =0 \\
& \Rightarrow s \frac{Y}{h L}=\frac{K}{h L}\left(\delta+g_{h}+g_{L}\right) .
\end{aligned}
$$

This leads to:

$$
\frac{Y}{L}=h\left(\frac{s\left(1-u-u \theta\left(1-i+R i^{*}\right)\right)^{\frac{1-\alpha}{\alpha}}}{\delta+u\left((1-i) \rho+i(1-\lambda) \phi+R i^{*} \lambda^{*} \phi^{*}\right)}\right)^{\frac{\alpha}{1-\alpha}} .
$$

Even though this expression may seem complex at first sight its interpretation is simple. All items which are listed in parentheses are constant. Therefore, output per capita grows at the same rate as the human capital stock given by

$$
g_{h}=u\left((1-i) \rho+i(1-\lambda) \phi+R i^{*} \lambda^{*} \phi^{*}\right) .
$$

Restricting student migration to balance in steady state requires an additional steady state condition. Ignoring other types of migration, the change in the Home labour force is the difference between the inflow of international foreign students who decide to stay in Home after education and the outflow of the respective Home international students who decide to stay in Foreign:

$$
\dot{L}=L^{*} u^{*} i^{*} \lambda^{*}-L u i \lambda
$$

Since in the steady state the labour force is required to be constant it follows that

$$
L^{*}=\frac{L u i \lambda}{u^{*} i^{*} \lambda^{*}} \text {. }
$$


Plugging this condition into the equations above allows us to solve for the steady state level and growth of Home if student migration is in balance.

\subsection{The effects of international education}

Ultimately, this paper seeks to analyse under what conditions international education is beneficial for a country using steady state output per capita without internationalisation in higher education as a benchmark. Generally, two types of effects are conceivable. In the long run, growth effects that lead to a change in growth of output per capita in steady state are of greatest interest. They generally follow from changes in the human capital accumulation equation. In the short run, level effects also affect growth rates, resulting in a lower steady state of capital per effective capita, but their impact on the growth rate is not permanent. In that spirit, level effects lead to short term increases or decreases in the growth rate while growth effects prevail in steady state. To investigate both we compare the steady state levels and growth without international education with those which include international education.

Starting with the case in which migration flows balance as a whole we can derive necessary conditions for internationalisation in higher education to be beneficial. We reproduce each country's steady state growth equation for convenience. Then, Home and Foreign respectively, will experience steady state growth equal to:

$$
\begin{aligned}
& g_{h}=u\left((1-i) \rho+i(1-\lambda) \phi+R i^{*} \lambda^{*} \phi^{*}\right) \\
& g_{h}^{*}=u^{*}\left(\left(1-i^{*}\right) \rho^{*}+i^{*}\left(1-\lambda^{*}\right) \phi^{*}+\frac{1}{R} i \lambda \phi\right) .
\end{aligned}
$$

To examine how international education affects the overall growth rate in both countries we can aggregate the growth rates. Assuming that output per capita in both countries is comparable, their respective population sizes can be used as weights. International education increases total growth in the countries if the following holds:

$$
\begin{aligned}
\frac{L u \rho+L^{*} u^{*} \rho^{*}}{L+L^{*}}<\frac{L u g_{h}+L^{*} u^{*} g_{h}^{*}}{L+L^{*}} & \\
& \Rightarrow i \rho+i^{*} R \rho^{*}<i \phi+i^{*} R \phi^{*} .
\end{aligned}
$$

Economic theory would predict that students only go abroad if it is more productive. If this assumption holds, it is beneficial for both countries together to open up for international students. The question remains, however, whether both countries separately benefit from internationalisation. Home will experience an increase in its growth rate if:

$$
u \rho<u\left((1-i) \rho+i(1-\lambda) \phi+R i^{*} \lambda^{*} \phi^{*}\right) .
$$

$R i^{*} \lambda^{*} \phi^{*}$ is always positive. This is not necessarily true for $(-i) \rho+i(1-\lambda) \phi$ which is positive only if

$$
\rho<(1-\lambda) \phi .
$$

Hence, the domestic productivity must be lower than the international productivity times the share of students that returns to Home. If this term is negative it has to be sufficiently small to make the steady state growth rate positive. A negative growth rate is only possible in either Home or Foreign, but not in both. In general, the country that receives and keeps the smaller share of foreign students faces a lower growth rate. 
The steady state growth rates determine the effects of internationalisation in the long run. In the short run, however, matters can turn out very differently. Immediately after the introduction of international student flows, the only effect is that the country that receives more students needs more teachers, while the other country needs fewer teachers. Since we assume the same teacher to student ratio in both countries, this implies that the aggregate short run effect is zero. For each country individually, however, this direct effect might be positive or negative depending on whether more or less members of the labour force are required for teaching.

$$
\begin{aligned}
s(1-u-u \theta)^{\frac{1-\alpha}{\alpha}}<s\left(1-u-u \theta\left(1-i+R i^{*}\right)\right)^{\frac{1-\alpha}{\alpha}} & \\
& \Rightarrow i<R i^{*} .
\end{aligned}
$$

To investigate the effects of internationalisation on growth if students migration leads to changes in the population of both countries a similar analysis is informative. The steady state growth rate in the home country is now equal to

$$
g_{h}=u\left((1-i) \rho+i(1-\lambda) \phi+i \lambda \phi^{*}\right) .
$$

Growth in both countries together is higher with international education if the following holds true.

$$
\begin{aligned}
& \frac{L u \rho+L^{*} u^{*} \rho^{*}}{L+L^{*}}<\frac{L u g_{h}+L^{*} u^{*} g_{h}^{*}}{L+L^{*}} \\
& \Rightarrow \rho+\frac{\lambda}{\lambda^{*}} \rho^{*}<\phi+\frac{\lambda}{\lambda^{*}} \phi^{*} .
\end{aligned}
$$

Again, this assumes that output per capita is comparable in the two countries so that population sizes can be used as weights. The term will always be positive if international students are rational and hence $\rho<\phi$. Moreover, a country is able to benefit individually from internationalisation in higher education if it holds that.

$$
\begin{aligned}
& u \rho<u\left((1-i) \rho+i(1-\lambda) \phi+i \lambda \phi^{*}\right) \\
& \quad \Rightarrow \rho<\phi+\frac{\lambda}{1-\lambda} \epsilon .
\end{aligned}
$$

This condition is always met if $\rho<\phi$. Moreover, we can see that in the long run, when migration is balanced, the growth rate increases with the productivity of education of domestic students in the foreign country. A certain share of these students returns to Home after graduation. Additionally, Home benefits by the international premium that Home students in Foreign gain. This effect increases if more foreign students decide to stay in Home after education.

Finally, we can have a look at the level effects in the case where student migration balances.

$$
\begin{aligned}
s(1-u-u \theta)^{\frac{1-\alpha}{\alpha}}<s\left(1-u-u \theta\left(1-i+\frac{\lambda}{\lambda^{*}} i\right)\right)^{\frac{1-\alpha}{\alpha}} & ; \\
& \Rightarrow \lambda<\lambda^{*}
\end{aligned}
$$

This means that if student flows balance the level effect is no longer dependent on the actual student inflow but on the probability that those students stay in the country. If the probability that home students stay abroad is smaller than the probability that foreign students stay in Home, the level effect is positive in the home country. 


\section{Empirics}

\subsection{Parameter callibration}

In order to apply the model it is essential to evaluate its parameters empirically. The exact share of international students depends on the country at hand. Within the model the internationalisation rate $i$ is measured in terms of the share of students which are educated in a foreign country. A broad comparison of those rates of internationalisation is possible with the help of a yearly assessment by Eurostat. According to their measurement, internationalisation within Europe averages 2.9 percent in 2012. However, given that not all international students register in the foreign country, the Eurostat figures are likely to be under-reported. This becomes visible at the example of the Netherlands, for which Nuffic collects data on a university level. While Eurostat reports that 2.3 percent of the Dutch students go abroad, Nuffic reports a rate of internationalisation of 7.1 percent in 2011. Since the Netherlands are below the European average in terms of outgoing students according to Eurostat 2012, the simulations are done for international shares between 5 and 10 percent.

Data quality is weaker when it comes to the probability to stay in a foreign country after graduation. In a recent paper, Bijwaard (2008), suggest that male study related migrants have a chance of 19 percent to stay in the Netherlands. For female students the chance is estimated at 26 percent. The values fluctuate strongly between different countries of origin. Moreover, these figures might be over reported. The data includes only students who register in the Netherlands and these have a higher probability to stay than students which do not even register in the first place. Hence the probability to stay used in the simulations is 15 percent.

To estimate the share of students in the labour force as measured by the model we consider the working population only. Eurostat data shows that men in Europe work between 40 and 46 years over their lifetime, while women work 36 to 44 years Brugiavini and Peracchi (2005). Moreover, university education is supposed to require three to four years for a Bachelor and four to six years for a Master degree. In reality even more time may be needed to finish university. Combining this information with the European target that 40 percent of the population should hold a university degree allows to calculate scores for the share of students. These range between roughly 2.5 percent and 7.5 percent, and hence, 5 percent will be used in the simulations.

Values for the teacher to student ratio $\theta$ can be found on the basis of data published by the European Commission. Currently, there is a total of roughly 19 million students in Europe, while higher education institutions employ 1.5 million staff members. Hence, $\theta$ should be close to 8 percent. This number neglects workers that work on buildings and equipment for the university sector.

Suppose there was no international education. Setting $i=i^{*}=0$, the human capital accumulation equation would reduce to $\dot{h}=h u \rho$ as in the original Lucas model. The parameter $\rho$, then, represents the growth of the human capital stock. In a sense, it is the return on human capital for every unit of human capital each time period. To evaluate plausible values for $\rho$ we make use of the vast literature estimating real returns to education. In their influential review paper, Psacharopoulos and Patrinos (2004) estimate the social return on investments into education to be 10.8 percent. In the context of our model every unit invested in human capital grows with rate $\rho$ and every one percent increase in 
human capital results in a $(1-\alpha)$ percent increase in output. To obtain an estimate for $\rho$ we hence use that

$$
r_{e d u} \approx \rho(1-\alpha)
$$

Setting $r_{e d u}=10.8$ and $\alpha=\frac{1}{3}$ gives an estimate for $\rho$ at 15.75 percent. The return in human capital that is specific to international education is given by $\epsilon$. This variable is important as it determines the extra learning gains from international education. Unfortunately, not much conclusive evidence exists on whether international education holds a return premium. However, several empirical studies have shown that students spending time abroad have benefited in terms of improved language skills and better cultural understanding (Freed (2004); Sutton and Rubin (1995)). Many verbal accounts, moreover, suggest that students undergo some personal development when going abroad. International experience, indeed, catches a wage premium in the labour market, but currently it is uncertain how much of it is attributable to selection Oosterbeek and Webbink (2006). Applying the same approximation as above $\epsilon=0.02$ implies a rate of return premium of about 1.3 percent.

\subsection{Simulations}

The model as formulated can be calibrated to fit many different pairs of countries. Whenever we compare our findings to an economy with purely domestic higher education, we name this economy "Lucas". Whenever we do this, we mean that we are comparing our results to the simplified version of the Lucas model rather than with the original. In the following section we will consider a pair that has the same parameter values except for size, where we assume that the labour force of the foreign country is initially four times larger. This setup roughly resembles the cases of Germany and the Netherlands. All parameter values used lie within the ranges established in the previous section. Thus, we let

$$
\begin{aligned}
& \alpha=\frac{1}{3}, \\
& s=\delta=0.1, \\
& \theta=0.08, \\
& u=0.05, \\
& i=0.1, \\
& \rho=0.15, \\
& \lambda=0.15 .
\end{aligned}
$$

Imagine this two-country world and suppose that international education does not carry any premium. Given that all parameters are identical with the exception of population size, we should expect to see a great surplus of students entering the small country every period of time. Since all students have the same probability to stay, the small country then faces a positive migration of well-qualified students as compensation for the initial increase in the cost of education. Figure 1 plots the development of both countries' income per capita relative to what it would have been without international education. The left panel assumes that the population size of both countries remains the same, and thus that student migration is offset by exogenous factors. The small country represented by the thick line initially starts off at a lower income per capita level. This decrease in 

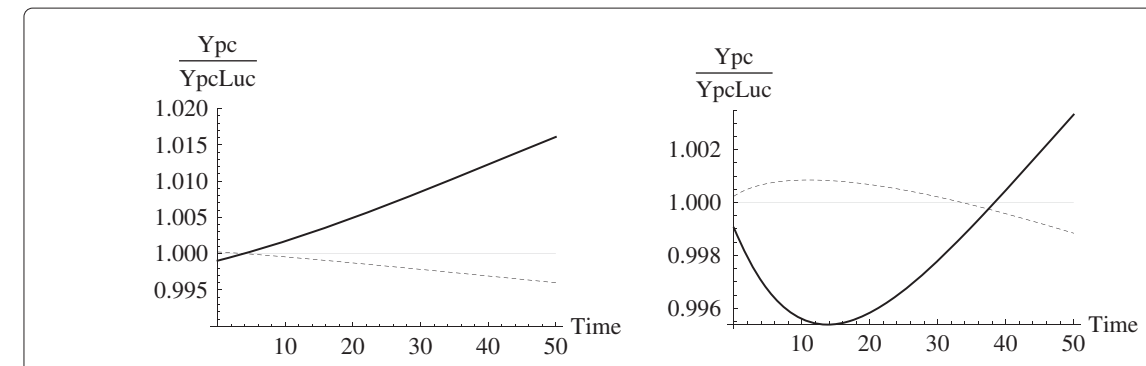

Figure 1 Base scenario without labour adjustments (left), with labour adjustment (right).

GDP per capita equals -0.084 percent. However, since it enjoys a larger growth rate, it reaches the no-internationalisation level of income within only four periods. Thereafter, brain gain leads to constantly higher levels of income than under the non-international "Lucas regime" and to 0.034 percent faster growth in steady state.

Table 1 gives additional comparative statics for this scenario relative to the domestic education economy, which, under our parameters for $u$ and $\rho$, grows at 0.75 percent in steady state.

If more students of the home country study abroad $(i=0.15)$ the extra steady state GDP-growth decreases. When the mobility of foreign students increases $\left(i^{*}=0.15\right)$ the steady state growth rate increases. A simultaneous increase in both mobility rates is more advantageous for the smaller than for the larger country. The same is true for the percentage students that stay in the country of study. An increase of the fraction of students that remain abroad negatively influences the growth rate, but the smaller country benefits more from a higher percentage of stayers than the larger country.

The right panel of Figure 1 shows what happens if the population size of both countries starts to change due to student mobility. Since for the Home country GDP growth is now accompanied by a population growth Home needs much more time to recover from its initial drop, and GDP per capita will grow slower. The reason for this is that the capital stock only adjusts gradually to the increased population size. If increase in the number of workers would be accompanied by an extra investment in capital, the growth patterns would look more like in the first panel. Figure 2 shows what happens in the very long run.

Table 1 Comparative statics for the left panel of Figure 1

\begin{tabular}{llllll}
\hline & \multicolumn{2}{c}{ NL } & \multicolumn{2}{c}{ DE } \\
\hline Rel. to Lucas & Init. $\Delta(\%)$ & Recov. in (t) & SS Gr.(\%) & Init. $\Delta$ & SS Gr. \\
\hline Base L. exog. & -0.084 & 4.00 & 0.034 & 0.021 & -0.0085 \\
\hline$i=0.15$ & -0.070 & 4.00 & 0.028 & 0.017 & -0.0071 \\
$i^{*}=0.5$ & -0.141 & 4.00 & 0.056 & 0.035 & -0.014 \\
$i=i^{*}=0.15$ & -0.126 & 4.00 & 0.051 & 0.032 & -0.013 \\
\hline$\lambda=0.2$ & -0.085 & 4.50 & 0.030 & 0.021 & -0.0075 \\
$\lambda^{*}=0.2$ & -0.085 & 2.75 & 0.049 & 0.021 & -0.012 \\
$\lambda=\lambda^{*}=0.2$ & -0.085 & 3.00 & 0.045 & 0.021 & -0.011 \\
\hline$\rho=\rho^{*}=0.2$ & -0.085 & 3.00 & 0.034 & 0.021 & -0.0085 \\
$\rho=\rho^{*}=0.1$ & -0.085 & 6.00 & 0.034 & 0.021 & -0.0085 \\
$\epsilon=\epsilon^{*}=0.02$ & -0.085 & 2.75 & 0.049 & 0.021 & 0.0044 \\
$\epsilon=\epsilon^{*}=0.05$ & -0.085 & 1.75 & 0.070 & 0.021 & 0.014 \\
\hline The first column gives the initial change of output per capita relative to Lucas. In the second column we give the time it needs to \\
reach the Lucas' level of output per capita again. The third column has the changes in the steady state growth rate due to \\
internationalisation in percentage points.
\end{tabular}



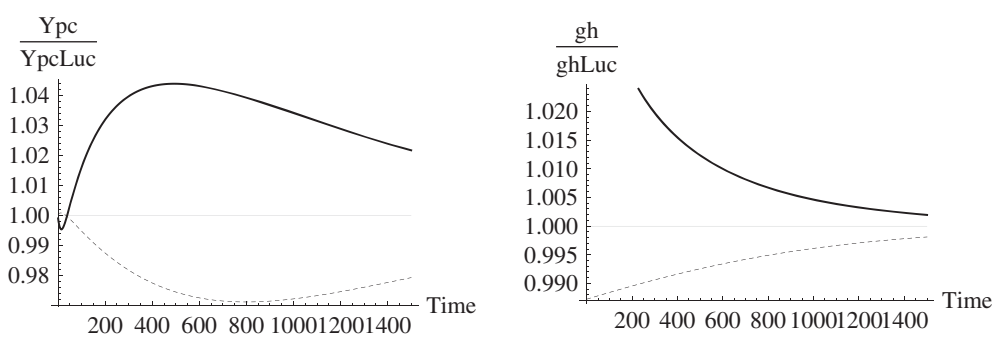

Figure 2 Long run adjustment of per capita income and human capital relative to Lucas when labour is endogenous.

With a constant increase in population the smaller country becomes larger and larger. This means that the mobility flows become more equal. The smaller country has more students and, therefore, also more students will study abroad. Eventually, the differences in population size will disappear and the growth effects vanish. It should be stressed that this result is a consequence of having constant and equal parameter values for $u, i, \lambda$ and $\rho$. If one country, for example, has a higher internationalisation rate, country sizes will not fully equalise in the long run.

Thus far, in the Figures we have only considered the purely distributional effects of international education. Figure 3 repeats the simulation assuming an international premium of two percent corresponding to about 1.3 percent greater returns to education. This corresponds to the penultimate row in Table 1. Relative growth rates of both countries increase across scenarios such that in either scenario both countries benefit from international education. Economic growth in the home country increases from 0.034 percentage points to 0.049 while for the foreign country a lower growth of -.0085 turn into a faster growth of 0.0044 . Based on these parameters economic growth in the smaller country would increase with 0.049 percentage points while GDP per capita would increase with 0.0044 percentage points. The average annual extra growth in both country therefore equals 0.013 percentage points.

This shows that at the most plausible values of the parameters international education is beneficial for both countries. Naturally, policy makers can attempt to increase their share of the overall gains, by targeting variables like the probability to stay through migration policy or by making it easier for foreign students to start studying. Even if no international premium exists, international education may be mutually beneficial. This is, for example, the case when one country has a higher productivity in educating students than the other country; a relationship we may see between a more and a less developed country. Under
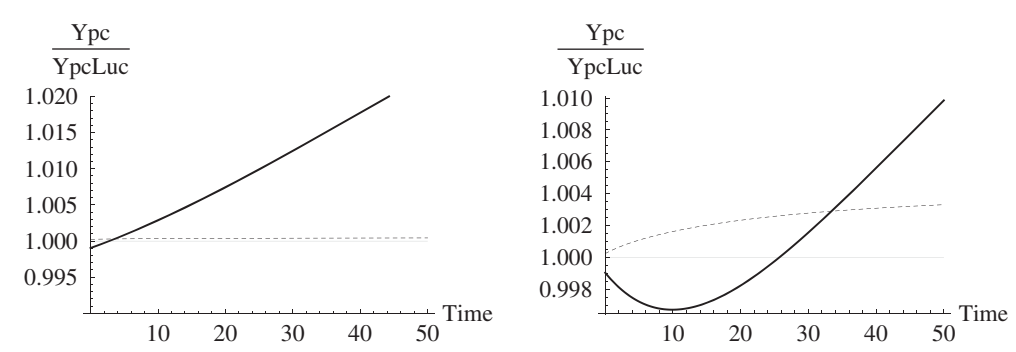

Figure 3 Scenario with $\epsilon^{*}=0.02$ without labour adjustments (left), with labour adjustment (right). 

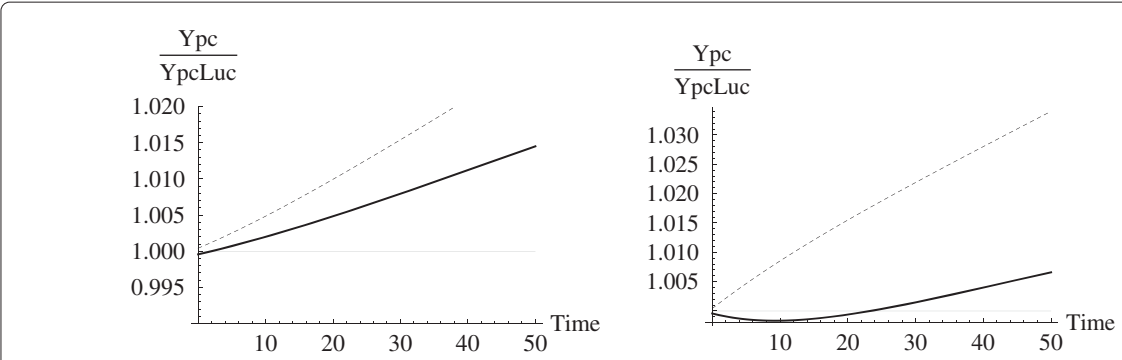

Figure 4 Case where countries are unsymmetric in most parameters except size: $\rho=0.2, \rho^{*}=0.1 ; i=0, i^{*}=0.2 ; \lambda^{*}=0.2$.

the assumption that only students from the less developed country want to study and stay in the more developed country, international education is universally beneficial as shown in Figure 4. Here, the less developed country benefits as the higher human capital of the students returning from the developed country outweighs the human capital loss from brain drain. The developed country loses in the short run due to the higher costs of education, but quickly recovers and gains from the inflow of talented students later on.

\section{Conclusions}

In this paper we developed an endogenous growth model to investigate the effects of internationalisation in higher education on economic growth. In aggregate, assuming that individual students only go abroad when that is beneficial to them, in the long run internationalisation is always beneficial for the two countries together. The distribution of the gains, however, depends on a variety of parameters like the rate of internationalisation and the probability to stay in a foreign country. While there are cases in which both countries gain, it is also possible that one country loses.

This implies that there can be two obstacles for the internationalization of university education. First, countries that emphasise short run effects in their decision making might try to limit access for foreign students. The reason for this lies in the costs of education which lower short term output. Second, an unequal division of the benefits of internationalisation might hamper international agreements about international cooperation. Since it will be hard for countries to stop students from studying abroad it will especially be difficult to benefit from internationalisation when the countries that receive students do not benefit from this, because a large fraction of the graduates leaves the country after the study. In a situation of high labour mobility a prisoner's dilemma might therefore occur. In the opposite extreme, if a substantial fraction of the students stays in the country of study, it will be attractive for each individual country to promote foreign students to study in their country. This could lead to a rat race in which countries attempt to get an as large as possible share of the flow of international students. Considering long-term growth, a country benefits if it attracts many foreign students who stay in the country. A policy to open up universities for foreign students is therefore complementary to a policy to make the labour market attractive for these foreign students.

\section{Endnotes}

${ }^{1}$ Lucas (1988) calculates the savings rate endogenously. We assume a constant savings rate as in Solow (1956). 
${ }^{2}$ All labour that is required to build and maintain the universities has to be counted as teachers in this model.

Competing interests

The IZA Journal of European Labor Studies is committed to the IZA Guiding Principles of Research Integrity. The authors declare that they have observed these principles.

\section{Acknowledgements}

We thank Jo Ritzen, the participants of the IIPF 2011 congress and of the Maastricht Macro Seminar for their useful comments. Furthermore, we gratefully appreciate the effort and comments of two anonymous referees.

Responsible editor: Martin Kahanec

\section{Author details}

${ }^{1}$ Bonn University, Bonn, Germany. ${ }^{2}$ Maastricht University, Maastricht, Netherlands. ${ }^{3}$ Nyenrode Business Universiteit, Breukelen, Netherlands. ${ }^{4} \mathrm{CES}$ ifo network, Munich, Germany.

Received: 19 November 2012 Accepted: 21 March 2013 Published: 18 April 2013

\section{References}

Bijwaard GE (2008) Immigrant migration dynamics model for The Netherlands. J Popul Econ 23: 1212-1247

Brugiavini A, Peracchi F (2005) The Length of working lives in Europe. JEur Econ Assoc 3: 477-486

Freed BF (1995) Second language acquisition in a study abroad context. John Benjamins Publishing Company, Amsterdam and Philadelphia

Lucas E (1988) On the mechanics of economic development. J Monetary Econ 22: 3-42

Mankiw NG, Romer D, Weil DN (1992) A contribution to the empirics of economic growth. Q J Econ 107: 407-437

McMahon W (2004) The social and external benefits of education. In: Johnes G Johnes J (eds). International Handbook on the Economics of Education. Edward Elgar Publishing Ltd. pp. 211-259

Mechtenberg L, Strausz R (2008) The Bologna process: how student mobility affects multi-cultural skills and educational quality. Int Tax Public Finance 15: 109-130

Oosterbeek H, Webbink D (2006) Assessing the returns to study abroad. CPB discussion Paper 64

Psacharopoulos G, Patrinos HA (2004) Returns to investment in education: a further update. Educ Econ 12: 111-134

Solow R (1956) A contribution to the theory of economic growth. Q J Econ 70: 65-94

Sutton RC, Rubin D (2004) The GLOSSARI project: Initial findings from a system-wide research initiative on study abroad learning outcomes. Front J 10:65-82

doi:10.1186/2193-9012-2-3

Cite this article as: Bergerhoff et al.: International education and economic growth. IZA Journal of European Labor Studies 2013 2:3.

\section{Submit your manuscript to a SpringerOpen ${ }^{\circ}$ journal and benefit from:}

- Convenient online submission

- Rigorous peer review

- Immediate publication on acceptance

- Open access: articles freely available online

- High visibility within the field

Retaining the copyright to your article

Submit your next manuscript at $\gg$ springeropen.com 